\title{
COMPARISON OF CLONIDINE AND ADRENALINE AS ADJUVANTS TO BUPIVACAINE IN SUPRACLAVICULAR APPROACH TO BRACHIAL PLEXUS BLOCK
}

\author{
Kumaresan $S^{1}$, Prasath $C^{2}$
}

${ }_{1}^{1}$ Assistant Professor, Department of Anaesthesiology, Melmaruvathur Adhiparasakthi Institute of Medical Sciences. ${ }^{2}$ Associate Professor, Department of Anaesthesiology, Melmaruvathur Adhiparasakthi Institute of Medical Sciences.

\section{ABSTRACT}

\section{BACKGROUND}

Aims and Objectives - In our study we compared the clonidine and adrenaline as adjuvants to bupivacaine in supraclavicular approach to brachial plexus block to prolong the duration of anaesthesia.

\section{MATERIALS AND METHODS}

It was a prospective, randomised, double-blinded study with eighty patients. The randomly allocated Group A [n $=40]$ received 40 $\mathrm{mL}$ of $0.25 \%$ Bupivacaine +200 micrograms of adrenaline and Group B [ $\mathrm{n}=40]$ received $40 \mathrm{~mL}$ of $0.25 \%$ bupivacaine +150 micrograms of clonidine in supraclavicular block. The onset of analgesia and motor blockade, duration of surgery, duration of motor blockade and analgesia, VAS score, vital parameters and sedation score were recorded, tabulated and analysed.

\section{RESULTS}

No difference in the onset of sensory and motor blockade in two groups. Duration of motor blockade and duration of absolute pain free period and duration of post-operative analgesia significantly prolong in clonidine group. No significant side effects were observed in either of the two groups.

\section{CONCLUSION}

Thus, we concluded that addition of clonidine to bupivacaine in supraclavicular approach to brachial plexus block significantly prolong the sensory and motor blockade with no side effects.

\section{KEYWORDS}

Clonidine, Adrenaline, Bupivacaine, Brachial Plexus, Supraclavicular Block.

HOW TO CITE THIS ARTICLE: Kumaresan S, Prasath C. Comparison of clonidine and adrenaline as adjuvants to bupivacaine in supraclavicular approach to brachial plexus block. J. Evolution Med. Dent. Sci. 2017;6(17):1305-1308, DOI: $10.14260 /$ Jemds/2017/283

\section{BACKGROUND}

Peripheral nerve block is usually performed for upper limb surgeries. The main purpose of the peripheral nerve block is not only to provide the intraoperative anaesthesia, but also it provides additional analgesic effect in the post-operative period without any systemic side effects. ${ }^{1}$ Local anaesthetics alone will not provide longer duration of analgesia, so adjuvants are added along with that to prolong the period. There are several additives used, but still ideal adjuvants are not found and under trial. ${ }^{2}$

Clonidine is an $\alpha-2$ adrenergic agonist drug. ${ }^{3-5}$ Usually by facilitation of $\mathrm{C}$-fiber blockade, vasoconstriction in the local area, slow retrograde axonal transport causes aggravation of the spinal blockade. Another way by which the alpha- 2 adrenergic agonist prolong the duration of analgesia is by simple diffusion along the nerves without any side effects. ${ }^{2}$

Several studies were done to prove the mechanism of prolongation of clonidine, but it is inconclusive. So we planned to do the peripheral nerve block with clonidine as an adjuvant drug along with bupivacaine.

Financial or Other, Competing Interest: None.

Submission 20-01-2017, Peer Review 13-02-2017,

Acceptance 19-02-2017, Published 27-02-2017.

Corresponding Author:

Dr. Kumaresan $S$,

Plot No. 34, Nethra Nivas,

Brindhammal Street,

Nithyanandham Nagar,

Villupuram-605602, Tamilnadu.

E-mail:drkums83@gmail.com

\section{MATERIALS AND METHODS}

The present study was conducted at Melmaruvathur Adhiparasakthi Institute of Medical Sciences and Research involving 80 patients. Ethical Committee approval was obtained for this prospective, randomised, controlled study. These patients were divided into two groups; 40 patients were assigned to clonidine group and 40 patients to adrenaline group after proper randomisation.

\section{Inclusion Criteria}

1. Age more than 20 years.

2. ASA I and II.

3. Upper limb surgeries.

\section{Exclusion Criteria}

1. Age less than 20 years.

2. ASA III and IV.

3. Drug allergy to local anaesthetics.

4. Patients in whom paraesthesia not elicited.

5. Failure of blockade.

6. Unwilling patients.

After obtaining informed consent, no pre-anaesthetic medications were given. IV line secured. Brachial plexus block performed by classic method of supraclavicular approach by paraesthesia technique.

\section{Clonidine Group}

$40 \mathrm{~mL}$ of $0.25 \%$ bupivacaine and $150 \mu \mathrm{g}$ clonidine was given to the patients. 


\section{Adrenaline Group}

$40 \mathrm{~mL}$ of $0.25 \%$ bupivacaine and $200 \mu \mathrm{g}$ adrenaline was given to the patients.

\section{Parameters Observed}

\section{Onset of Analgesia}

Onset of analgesia was taken as abolishment of pin prick pain over the distribution of ulnar and median nerve. Patients were assessed every minute.

\section{Onset of Motor Blockade}

Onset of motor block was assessed every two minutes after the block using four point scales -

0 - Normal power.

1 - Able to move arm, but weakness.

2 - Fingers can be moved, but not able to move arm.

3 - Complete motor block.

A score of 2 was considered as onset of motor block.

\section{Surgery Duration \\ Motor Blockade Duration}

The time taken for a score of 3 to become 2 score in a four point scale is considered as motor blockade duration.

\section{Duration of Analgesia}

Visual Analogue Scale (VAS) was used for pain assessment. VAS has $10 \mathrm{cms}$ length, numbered from 0 to 10 . After explaining clearly about the VAS to the patients as 0 - no pain and 10 - the worst possible pain, the patient themselves was asked to score the pain level according to VAS. Postoperatively, the patients were observed every half an hour till the motor blockade is reversed. After that every 60 minutes (hourly) for 6 hours, 120 minutes ( $2^{\text {nd }}$ hourly) for next 6 hours and 24 hours later.

\section{Duration of Absolute Pain Free Period}

If the patient did not have any pain in the post-op period is called as absolute pain free period (VAS - 0 ).

\section{Duration of Postoperative Analgesia}

The time period from the onset of analgesia to requirement of analgesia (VAS $>5$ ).

\section{Vital Parameters}

1) Pulse rate, 2) Blood pressure, 3) Respiratory rate, monitored periodically.

\section{Sedation Score}

Ramsay sedation score

0 - Fully awake.

1 - Drowsy.

2 - Drowsy, but arousable on touch or call.

3 - Drowsy, but arousable on deep stimuli.

4 - Somnolent.

Side effects noted are hypotension and bradycardia.

Patients in whom the block was unsuccessful due to total failure of missed dermatomes, which needed intravenous supplementation or general anaesthesia were excluded from the study.

\section{Statistical Tool}

Data analysis was done using Epi Info 2008 version. Means, standard deviations, chi square and " $p$ " values were calculated. Yate's test was used to find the qualitative variables. Kruskal-Wallis chi-square test was used with " $p$ " less than 0.05 is considered significant for quantitative variable.

\section{RESULTS}

In our prospective, randomised, controlled study type of surgery, gender, weight and age were similar in both groups (Table 1).

\section{Onset of Sensory Block}

In Adrenaline Group, onset of sensory block varied from 6 to 12 minutes with a mean value of 9.17 minutes with a standard deviation of 1.56. In Clonidine Group, it varied from 7 to 12 minutes with a mean value of 8.77 minutes and standard deviation 1.13 (Table 2).

\section{Onset of Motor Blockade}

In Adrenaline Group about 10 to 18 minutes of motor block was seen with mean and standard deviation of 14.13 minutes and 1.67, whereas in clonidine the time ranges from 10 to 16 minutes with a mean and standard deviation of 13.78 minutes and 1.27 (Table 2).

\section{Duration of Surgery}

In Adrenaline Group, time varied from 90 to 240 minutes with a mean and standard deviation of 107 minutes and 24.4. In Clonidine Group, the time varied from 90 to 150 minutes with a mean and standard deviation of 113.8 minutes and 14.3 (Table 2).

\section{Duration of Motor Blockade}

In Clonidine Group, the duration was found to be prolonged to 480 to 620 minutes with a mean and standard deviation of 550.8 minutes and 28.7, but in Adrenaline Group the time was found to be decreased to 250 to 330 minutes with a mean and standard deviation of 280.75 minutes and 18.7 (Table 2).

\section{Duration of Absolute Pain Free Period}

In Clonidine Group, the duration was found to be prolonged to 500 to 720 minutes with a mean and standard deviation of 643.8 minutes and 36.6, but in Adrenaline Group the time was found to be decreased to 330 to 480 minutes with a mean and standard deviation of 371.4 minutes and 27.5 (Table 2).

\section{Duration of Postoperative Analgesia}

In Clonidine Group the duration was found to be prolonged to 840 to 1080 minutes with a mean and standard deviation of 959.3 minutes and 38.3, but in Adrenaline Group the time was found to be decreased to 480 to 670 minutes with a mean and standard deviation of 564.8 minutes and 24.2 (Table 2).

\section{Sedation Score}

In Adrenaline Group it was mean $0.2 \pm 0.1$, in Clonidine Group it was mean $1.7 \pm 0.51$ (Table 2). 


\begin{tabular}{|c|c|c|c|}
\hline Variable & $\begin{array}{c}\text { Adrenaline } \\
\text { Group }\end{array}$ & $\begin{array}{c}\text { Clonidine } \\
\text { Group }\end{array}$ & 'P' value \\
\hline Age (Years) & $34.6 \pm 15.5$ & $34.9 \pm 12.7$ & 0.5502 \\
\hline Weight (Kg) & $60.3 \pm 5.0$ & $61.7 \pm 5.0$ & 0.2847 \\
\hline Gender (M:F) & $31: 9$ & $28: 12$ & \\
\hline \multicolumn{3}{|c|}{ Table 1. Demographic Data } \\
\hline
\end{tabular}

\begin{tabular}{|c|c|c|c|}
\hline Parameter & $\begin{array}{c}\text { Adrenaline } \\
\text { Group }\end{array}$ & $\begin{array}{c}\text { Clonidine } \\
\text { Group }\end{array}$ & 'P' value \\
\hline $\begin{array}{c}\text { Onset of Sensory } \\
\text { Block (Minutes) }\end{array}$ & $9.17 \pm 1.56$ & $8.77 \pm 1.13$ & 0.2206 \\
\hline $\begin{array}{c}\text { Onset of Motor } \\
\text { Block (Minutes) }\end{array}$ & $14.13 \pm 1.67$ & $13.78 \pm 1.27$ & 0.2362 \\
\hline $\begin{array}{c}\text { Duration of } \\
\text { Surgery } \\
\text { (Minutes) }\end{array}$ & $107 \pm 24.4$ & $113.8 \pm 14.3$ & 0.0755 \\
\hline $\begin{array}{c}\text { Duration of } \\
\text { Motor Blockade } \\
\text { (Minutes) }\end{array}$ & $280.75 \pm 18.7$ & $550.8 \pm 28.7$ & 0.0001 \\
\hline $\begin{array}{c}\text { Duration of } \\
\text { Absolute Pain } \\
\text { Free Period } \\
\text { (Minutes) }\end{array}$ & $371.4 \pm 27.5$ & $643.8 \pm 36.6$ & 0.0001 \\
\hline $\begin{array}{c}\text { Duration of } \\
\text { Postoperative } \\
\text { Analgesia } \\
\text { (Minutes) }\end{array}$ & $564.75 \pm 24.2$ & $959.3 \pm 38.3$ & 0.0001 \\
\hline Sedation Score & $0-1$ & $1-2$ & 0.0001 \\
\hline \multicolumn{2}{|c|}{ Table 2. Parameters } \\
\hline
\end{tabular}

\section{DISCUSSION}

Alpha-2 agonist like clonidine was introduced in the early 1960s as a nasal decongestant. During its use, a nasal decongestant, the antihypertensive property of drug was found out. Subsequently, more insights into the pharmacological properties have led to its use in clinical anaesthetic practice as well.

Clonidine assumes greater importance as anaesthetic adjuvant and analgesic. Sympatholytic is the primary effect. The main action of the clonidine is the decreases in the level of peripheral norepinephrine release by stimulating the prejunctional inhibitory $\alpha-2$ adrenoreceptors. It inhibits central neural transmission in the dorsal horn by presynaptic and postsynaptic mechanism and directly in spinal preganglionic sympathetic neurons. Traditionally, it was used as an antihypertensive drug, but nowadays the uses is mostly based on its analgesic, sedative and anxiolytic properties being developed. The release of endogenous encephalin-like substances was mediated by the peripheral action of clonidine and was first reported by Nakamura et al in 1988.6

In 1991, Maze and Tranquil et al reported that alpha-2 adrenergic agonists has an analgesic activity like a potent opioid, is anxiolytic and sedative as benzodiazepine and sympatholytic and its action is reversible. ${ }^{7}$ In peripheral nerve blockade, adjuvants added to the local anaesthetics may increase the duration of intraoperative and postoperative anaesthesia. Clonidine has central analgesic action. In addition to its central action, the peripheral antinociception by an $\alpha-2$ adrenoreceptor-mediated local release of encephalin like substances is also seen. ${ }^{8}$

In peripheral nerve and central neuraxial blockade both sensory and motor blockade of local anaesthetics are prolonged by clonidine. Conduction of $\mathrm{C}$ and $\mathrm{A}$ gamma fibers was blocked by local anaesthetics, which is intensified by clonidine. Clonidine may modify the action of local anaesthetics in sodium channel, either directly or indirectly.

By statistical analysis the duration of surgery, age and weight in the two groups was not found to be statistically significant with a $\mathrm{p}$ value of $0.5502,0.7508$ and 0.0755 ( $p>0.05$ ). So both groups were comparable.

\section{Onset of Sensory Blockade}

Clonidine group had a mean onset of sensory blockade of 8.77 \pm 1.13 minutes similar to the adrenaline group with $9.17 \pm$ 1.56 minutes. The two groups were found to be statistically insignificant with a p value of 0.2208 ( $p>0.05)$.

\section{Onset of Motor Blockade}

Clonidine group had a mean onset of motor blockade of 13.25 \pm 1.37 minutes similar to the adrenaline group with $14.1 \pm$ 1.67 minutes. The two groups were found to be statistically insignificant with a p value of $0.0744(p>0.05)$. Similar to the present study, Eledjam $\mathrm{JJ}_{\mathrm{J}}$ et $\mathrm{al}^{9}$ and Popping Daniel $\mathrm{M}$ et al ${ }^{8}$ also concluded that there was no difference in the onset of sensory and motor blockade when clonidine was added to the local anaesthetic solution.

\section{Duration of Motor Blockade}

The mean duration of motor blockade in clonidine group was $550.8 \pm 28.7$ minutes, whereas in the adrenaline group with $280.75 \pm 18.7$ minutes. The two groups were found to be statistically significant with a p value of $0.0001(\mathrm{p}<0.05)$ Similar to the present study, Eledjam JJ et $\mathrm{al}^{9}(580.4 \pm 38.7$ minutes, 290.6 \pm 34.5 minutes) and Popping Daniel $\mathrm{M}$ et al ${ }^{8}$ also concluded that clonidine prolongs the duration of motor blockade when added to the local anaesthetic solutions.

\section{Duration of Absolute Pain Free Period}

Clonidine group had an absolute pain free period of $643.8 \pm$ 36.6 minutes, whereas in the adrenaline group with $371.4 \pm$ 27.5 minutes. The two groups were found to be statistically significant with a p value of $0.0001(\mathrm{p}<0.05)$. Similar to the present study Eledjam JJ et $\mathrm{al}^{9}$ and Popping Daniel $\mathrm{M}$ et $\mathrm{al}^{8}$ also concluded that clonidine prolongs the duration of motor blockade when added to the local anaesthetic solutions.

\section{Duration of Postoperative Analgesia}

Clonidine group had a duration of post-operative analgesia of $959.3 \pm 38.3$ minutes, whereas in the adrenaline group with $564.75 \pm 24.2$ minutes. The two groups were found to be statistically significant with a p value of $0.0001(\mathrm{p}<0.05)$. Similar to the present study, Eledjam JJ et $\mathrm{al}^{9}$ (in clonidine group it was $994.2 \pm 34.2$ minutes compared to adrenaline group it was $728.3 \pm 35.8$ minutes) and Popping Daniel $M$ et $\mathrm{al}^{8}$ also concluded that clonidine prolongs the duration of motor blockade when added to the local anaesthetic solutions.

\section{Sedation Group}

The sedation score in Group B it was mean $1.72 \pm 0.51$, in Group A it was mean $0.2 \pm 0.1$. In clonidine group since the sedation score was not more than 2, the respiratory function was not compromised, so intraoperative sedation is well observed in clonidine group. 


\section{Side Effects}

Patients were observed for the side effects, such as hypotension and bradycardia. In both groups, there is no incidence of hypotension and bradycardia. No complications related to brachial plexus block were observed.

\section{CONCLUSION}

When compared to the adrenaline, clonidine added to local anaesthetic solution in supraclavicular approach to brachial plexus block prolongs the duration of postoperative analgesia and motor blockade.

\section{REFERENCES}

[1] Damien MB, McCartney CJ, Vincent CW. Novel analgesic adjuvants for brachial plexus block: a systemic review. Anesthesia \& Analgesia 2000;90(5):1122-8.

[2] Gaumann DM, Brunet PC, Jirounek P. Clonidine enhances the effects of lidocaine on C-fiber action potential. Anesthesia \& Analgesia 1992;74(5):719-25.

[3] Iskandar H, Guillaume E, Dixmérias F, et al. The enhancement of sensory blockade by clonidine selectively added to mepivacaine after midhumeral block. Anesthesia \& Analgesia 2001;93(3):771-5.
[4] Erlacher W, Schuschnig C, Orlicek F, et al. The effects of clonidine on ropivacaine $0.75 \%$ in axillary perivascular brachial plexus block. Acta Anaesthesioogica Scandinavica 2000;44(1):53-7.

[5] Iskandar H, Benard A, Ruel-Raymond J, et al. The analgesic effect of interscalene block using clonidine as an analgesic for shoulder arthroscopy. Anesthesia \& Analgesia 2003;96(1):260-2.

[6] Nakamura M, Ferreira SH. Peripheral analgesic action of clonidine: mediation by release of endogenous enkephalin-like substances. European Journal of Pharmacology 1988;146(2-3):223-8.

[7] Maze M, Tranquilli W. Alpha-2 adrenergic agonists: defining the role in clinical anesthesia. Anesthesiology 1991;74(3):581-605.

[8] Pöpping DM, Elia N, Marret E, et al. Clonidine as an adjuvant to local anesthetics for peripheral nerve and plexus blocks: a meta-analysis of randomized trials. Anesthesiology 2009;111(2):406-15.

[9] Eledjam JJ, Deschodt J, Viel EJ, et al. Brachial plexus block with bupivacaine: effects of added alphaadrenergic agonists: comparison between clonidine and epinephrine. Canadian Journal of Anaesthesia 1991;38(7):870-5. 